Title: Delivering to 'that list': The challenges of working with Learning Outcomes

\title{
Authors:
}

H.L. Bateman ${ }^{1}$

Clinical Trainer in Restorative Dentistry / Honorary Clinical Senior Lecturer

G.I. McCracken ${ }^{1}$

Clinical Senior Lecturer / Honorary Consultant in Restorative Dentistry

J.S. Ellis ${ }^{1}$

Professor of Dental Education / Honorary Consultant in Restorative Dentistry

J. Stewart ${ }^{2}$

Senior Lecturer in Clinical Education

Affiliations: ${ }^{1}$ School of Dental Sciences, Newcastle University, UK

${ }^{2}$ School of Medical Education, Newcastle University, UK 


\begin{abstract}
Dental education providers have raised concerns around the challenges experienced when trying to demonstrate student attainment of 'professionalism' as described in the General Dental Council (GDC) document 'Preparing for Practice'. This manuscript describes a documentary analysis of each 'outcome' within the dentist Professionalism domain section, with an assessment of whether it met the criteria of a functional learning outcome. In addition, outcomes were scrutinised in terms of application within undergraduate degree programmes.
\end{abstract}

Key challenges identified were: The 'outcome list' included standards, objectives as well as outcomes; Not all statements were specific and focused, some were broad and multi-faceted; Determining attainment where there was no identifiable end-points; Judging achievability within the supervised and confined environment of undergraduate programmes.

We conclude that issues have been created through the way that these learning outcomes have been expressed. Also, it is evident that there are ideological and philosophical issues about accurately articulating the attainment of complex phenomena like professionalism. The findings from this study reflect the challenges associated with using learning outcomes to adequately capture professionalism, the values that underpin it and the behaviours that manifest its existence in clinical practice. 


\section{Delivering to 'that list': The challenges of working with Learning Outcomes}

\section{Background}

In the UK, the General Dental Council (GDC), as the regulator of dental professionals, has responsibility for the quality assurance of training programmes. To this end, they produce documentation outlining the requirements for education and training. One such document, 'Preparing for Practice: Dental team learning outcomes for registration', ${ }^{1}$ describes the learning outcomes that are required to be attained under four domains:

- Clinical;

- Communication;

- Professionalism;

- Management and Leadership.

Education providers must demonstrate compliance with, and alignment to, all of these requirements.

The use of learning outcomes is well established in the educational literature, with significant amounts written on what constitutes an 'ideal' outcome along with guidance on which taxonomies to employ when writing learning outcomes. ${ }^{2-8}$ Learning outcomes have differing purposes, dependant on the stakeholder. ${ }^{9}$ For students, outcomes can signpost elements of a programme and enable self-directed study and assessment of understanding and development. ${ }^{10}$ Programme providers can use outcomes to not only express a focussed endpoint but also to inform and align curriculum design and delivery and assessment strategy. 
Alongside the shift in how products of learning are expressed, both medicine and dentistry have moved from an implicit understanding of professional conduct, to overt reference and attempted itemisation of professionalism within the curriculum. ${ }^{11-13}$ This has been reinforced by the requirements of external regulatory bodies that education providers demonstrate attainment through assessments of specific learning outcomes associated with being a 'professional'. 1, 14 The use of outcomes by the GDC for specifying attainment requirements, implies that 'professionalism' can be described, with the use of learning outcomes, in a comparable way to other elements in the curriculum, for example clinical skills. However, the clinical education literature acknowledges the wide-ranging challenges of integrating the diverse values within a profession into measurable behaviours of its newly-formed clinicians. ${ }^{15-17}$ A potential disconnect therefore exists between the application of regulatorproduced outcomes and the complexity of the lived-phenomenon referred to as 'professionalism'. The current descriptors present education providers with significant challenges: what to demonstrate, how to deliver these and what to record.

This study stems from our belief that by problematising the issues faced by education providers when responding to the set of learning outcomes, we can then look toward proposing a format and presentation of attainment that will satisfy the dual functions of feasibility for the provider and assurance for a regulator.

The overarching aim of this study was to critically review the utility of the GDC's prescribed list of 'professionalism' learning outcomes to the dental undergraduate education context. 


\section{Method}

\section{Overarching conceptual approach}

In analysing the learning outcomes the researchers adopted a pragmatic approach; ${ }^{18}$ putting aside the challenges associated with conceptualising professionalism and acknowledging that educational providers must still be compliant with the documentation produced by a regulator. The outcomes were therefore evaluated according to their utility and the consequences of applying them within an undergraduate context. ${ }^{19}$

The outline of the method followed in this study is displayed in Figure 1.

\section{Data source overview}

The current GDC 'Preparing for Practice' document, last updated in 2015, was the focus of this analysis. The document is freely available in the public domain and via the internet on the GDC website, published in pdf format. ${ }^{1}$ It specifies that it is applicable to 'all courses that lead to registration with the GDC'. It was analysed in isolation from other documentation, albeit there were references within the text to other GDC produced documents.

\section{Initial data analysis}

The initial sorting of statements was conducted by HB. The learning taxonomy selected to act as a frame to analyse statements was Bloom's taxonomy, ${ }^{4,5}$ as this is the most widely used, applied and understood taxonomy within higher education. Bloom's taxonomy is a hierarchical taxonomy with 3 domains of learning: Cognitive (knowledge-based), affective (attitudes, emotions, feelings) and psychomotor (skills-based). An example of the cognitive domain at the lowest end of the hierarchy might be the ability to 'list' items or 'define' 
something. Higher level within the cognitive domain may include the ability to 'synthesise' information and perform a 'critique'.

Using documentary analysis techniques, ${ }^{20}$ each GDC professionalism 'outcome' was reviewed to assess whether it met the criteria of a functional learning outcome: its clarity of meaning, explicit reference to a level of cognitive, psychomotor or affective attainment and its compatibility with existing assessment processes. In addition, the outcomes were considered in relation to the practical challenges of demonstrating an overt and behavioural manifestation of achievement within an undergraduate degree programme.

Outcomes were analysed in terms of how tangible (ability to be applied) they were, this included presence of a clear endpoint, indication of scope of breadth and depth of content, and direction on how assessment could be conducted. The action verb component of each 'outcome' was considered, both in terms of Bloom's taxonomy domains and levels. An excel spreadsheet format was used to record these data.

\section{Production of summary documentation}

When essential components for 'learning outcomes' were absent, other classifications were considered for the professionalism statements. These included, from the abstract to more concrete: Principle, Standard; Objective and Outcome, which was further divided into outcomes with challenges with regards to feasibility and also function. The descriptors for each of these classifications are shown in Table 1. The use of the term 'competencies' was not included in this study as these are associated with completion of specific actions and tasks, so were not included on the continuum of education goals.

\section{Revision, final analysis of document and validation}

Consideration was given to the practical challenges of implementing each 'outcome' and consideration given to whether the learner, working under supervision in a learning 
environment, has opportunity to demonstrate the traits and skills as stipulated within the outcome.

Statements were critically reviewed and annotated, making notes regarding whether the 'gold standard' for the above features were met by the descriptors, also drawing on the collective experience of the authors as clinical educators to consider the practicalities of demonstrating attainment in the context of a learner in a supervised environment.

The analysis findings were critically reviewed by all researchers in a validation process, revisiting initial classification and annotations to confirm the approach as described below:

\section{Assurance of analytic rigour}

The rigour of the analytic process was supported by recursive analysis ${ }^{21}$ and using memoing ${ }^{22}$ to record analytical choices. Transparency of coding allowed decisions to be overt and open to scrutiny by other researchers (Table 1).

In terms of reflexivity, ${ }^{23,24}$ each member of the research team brought different experiences, skills and perspectives in the scrutiny of the data including experience of curriculum mapping and assessment blue-printing, experience in the practicalities of design and implementation of assessments for the undergraduate curriculum. Open discussion and exploration of each others opinions enabled a non-biased conclusion to be achieved through a reflexive approach. Peer review ${ }^{22}$ was crucial to the rigour of the analysis as it allowed crystallisation ${ }^{25}$ of the approach rationale and justification of the classification made in the analysis. When there was disagreement between researchers, the group reviewed the rationale, descriptors and their application, before reaching consensus. Following this, remaining outcomes where rereviewed to ensure any modifications in analysis were applied consistently. 


\section{Results}

Twenty outcomes formed the Professionalism domain of the Preparing for Practice document. The analysis of each 'outcome' is shown in Table 2.

Issues identified had two main foci, firstly on why they fail as outcomes and secondly, why these 'outcomes' present challenges if ensuring attainment of 'professionalism'. These are summarised in Figure 2 and illustrative examples are described below.

\section{Illustrative examples of findings}

The action verb in some 'outcomes' was readily identifiable, making assignment of a Bloom's taxonomy learning domain and level within that domain straightforward. An example of this is GDC outcome 8.3, which has the action verb 'explain' and is therefore part of the cognitive domain, at the level of 'understanding':

GDC 8.3 'Explain the contribution that team members and effective team working makes to the delivery of safe and effective high quality care' 1

However, in some instances, the identification of the action verb proved challenging (both the domain and level) with no specific behaviour stated but instead a statement of instruction, suggesting an objective rather than an outcome:

GDC 8.2 'Ensure that any team you are involved in works together to provide appropriate dental care for patients' 1

When considering the above example, ensuring a 'team' is working together may contain affective components, cognitive elements of knowing how and why teams may work more effectively and in addition could include practical task application. It is also relevant to acknowledge that within an undergraduate dental programme, students are not operating as independent practitioners. This raises questions for some statements whether there is ability to truly demonstrate achievement independently in a supervised environment, or whether it should be considered as aspirational. 
In assigning a 'level' to fulfil Bloom's taxonomy, challenges also arose when the verb within the statement was not specifically listed in the taxonomy. On these occasions, a judgement was made based on clinician / clinical educator experience of what was being asked for in the outcome, and the necessary skills to achieve this. For example:

GDC 7.1 'Be familiar with and act within the GDC's standards and within other professionally relevant laws, ethical guidance and systems' 1

This example includes phrases that would normally be avoided when writing learning outcomes. Although 'be familiar with' suggests a cognitive process that could be assessable, it does not articulate or allude to how 'familiarity' will be demonstrated by behaviours and to what level of expertise it will be practiced. The 'act' within the outcome is more difficult to tangibly assess, but this could be considered 'achieved' if there had been an absence of concerns raised (i.e. no reports of concern where the student has not achieved the specified components of an outcome). The 'outcome' also has a broad scope and multiple component elements; the range of laws, ethical guidance and systems is extensive, so would not be assessed in single assessment episode. 'Familiarity' could be assessed at a point in time, however 'acting within' implies a more longitudinal activity.

Whilst the style of some outcomes conformed to the expectations detailed in the descriptor of an 'outcome' (Table 1.), others were styled with elements of a standard. For example GDC 6.2:

GDC 6.2 'Be honest and act with integrity' '1

In terms of assessment opportunities, some of the 'outcomes' did not identify an obvious quantifiable opportunity for assessment:

GDC 6.5 'Recognise and respect the patient's perspective and expectations of dental care and the role of the dental team taking into account current equality and diversity legislation, noting that this may differ in England, Scotland, Wales and Northern Ireland' 1 
There are elements of both the cognitive domain, possibly at the 'remembering' level if 'recognise' is taken as the action verb, but also an affective component in terms of 'respect' which may indicate a 'value' level within the affective domain. 'Respect' is technically an outcome as it is in Bloom's taxonomy affective domain (at different levels), but is difficult to measure as it relies on an ability to assess such attitudes. It is therefore difficult to design an assessment by which an education provider could tangibly and consistently assess the way in which a student has 'respect' for patients' expectations. Two further examples of similar challenges in application and representativeness of 'professionalism' are:

\section{GDC 6.3 'Respect patients' dignity and choices' 1}

GDC 7.3 'Act without discrimination and show respect for patients, colleagues and peers and the general public' 1

In these a student's behaviour could be 'assessed' at a moment in time and for a given scenario, but this may not represent specific attitudes or give the longitudinal maintenance of attributes which are key to the consideration of complex phenomena such as professionalism.

\section{Discussion}

Given that the purpose of the GDC document 'Preparing for Practice' is to support quality assurance across all dental education providers, this study identifies a risk that the quality of the learning outcomes could, themselves, result in differing interpretations. By being unclear, the outcomes are likely to defeat the purpose of having a standardised document for all providers of dental education. The complexity of the 'style' may however not be the 'fault' of the writers of the document, but rather that attempting to describe a complex phenomenon such as professionalism in this format of educational goals just does not 'work'.

This study demonstrates that very few of the 'outcomes' in the Professionalism domain of Preparing for Practice, when taken in their entirety, are written as outcomes from the 
perspective of their application in an education environment. This situation has implications for education providers from a local governance perspective when designing curricula and assessments and when mapping and preparing blueprints. The challenges of providing broad outcomes has been described in the literature and includes how they are interpreted by both students and education providers, and how they are mapped to other requirements. ${ }^{26}$ When outcome statements include subsections within them, how providers interpret a partially attained outcome, provides an element of uncertainty and potentially inconsistency across providers. Differing interpretation of 'attainment' from what might be described as 'woolly' and inaccurately articulated 'outcomes' has the potential to undermine the apparent purpose of having universal 'outcomes' from regulators. Similar challenges arise when 'outcomes' are so broad in terms of scope and content that it becomes difficult to determine exactly what assessment(s) would be needed to judge attainment.

In terms of assessment opportunities, some 'outcomes' did not identify an obvious quantifiable opportunity for assessment. In many of these cases recognising an absence of the described attributes may provide a possible attainment indication of the desired outcome. Successful attainment may therefore require an approach of identifying those who are not demonstrating the 'outcome'. Challenges also existed when there was no established assessment tool, which was reproducible, valid and reliable. Currently, there are no accepted robust tools to consider assessment of attitudes and beliefs, with reliance on observable behaviours. This approach has weaknesses and from a practical perspective, demonstration of attainment presents challenges. ${ }^{16,17,27}$ From the perspective of compliance with regulatory requirements, the key consequences of an absence of obvious assessment tools is that training providers can demonstrate successful attainment irrespective of differing interpretations between providers and may not support regulator confidence in consistent attainment. 
More complex and difficult to resolve, our findings suggest that articulating complex social processes as 'learning outcomes' is likely to be flawed. By utilising a format that in itself is quite prescriptive and mechanistic, there is a risk of losing the 'richness' of complex phenomena such as professionalism, reducing it to the denominators or surrogates which can be described and assessed. However, with learning outcomes so widely adopted and integrated into how educational attainment is expressed, it may be difficult to have alternate formats recognised and adopted.

Therefore, by presenting the professionalism requirements of the regulator as outcomes, which themselves do not conform to an established educational format, there is a risk of compounding the challenges education providers have in demonstrating attainment of with 'professionalism' and also undermine the educational role and benefit of true, well-designed learning outcomes.

The challenges identified in this manuscript associated with working to regulator specified outcome documents are not specific to dentistry and these challenges are amplified by focusing the inquiry on the 'Professionalism' domain of this GDC document. Issues which have become evident also relate to more ideological and philosophical questions about accurately articulating attainment of complex phenomena. Moving forward, it will be critical to consider these concepts to better understand and then have confidence in what professionalism is, how it can be demonstrated and maintained throughout a professional's life. Careful and fair consideration by stakeholders including the public, patients, regulators, professionals and those who support the development of professionals is needed, to develop both an informed and deliverable perspective. 


\section{Conclusion}

Critical review of the utility of the GDC's prescribed list of 'professionalism' learning outcomes identified attainment challenges from the perspective of the education provider. There is justification to re-open the debate about the complexity of judging professionalism and address the current mis-match of managing complex phenomena with educational goals. 
Table 1. Descriptors developed in this study for identification of educational goal 'style' in statement presentation

\begin{tabular}{|c|c|}
\hline Principle & $\begin{array}{l}\text { An approach that should be applied to activities undertaken (as a } \\
\text { professional). }\end{array}$ \\
\hline Standard & $\begin{array}{l}\text { An approach that should be applied to all activities undertaken } \\
\text { (as a professional). Provides an indication of the appropriate } \\
\text { level which is expected to demonstrate achievement. }\end{array}$ \\
\hline Objective & $\begin{array}{l}\text { An expression of the intended educational purpose from the } \\
\text { perspective of the educator. The delivery and direction has been } \\
\text { outlined. }\end{array}$ \\
\hline $\begin{array}{l}\text { Outcome with } \\
\text { feasibility challenges }\end{array}$ & $\begin{array}{l}\text { Where the statement contains the characteristics of a learning } \\
\text { outcome, but in terms of practical application, challenges arise: } \\
\text { Technically defines an endpoint and has an action verb to } \\
\text { describe the level of this expectation, but with current available } \\
\text { assessment tools not possible to assess attainment of this } \\
\text { outcome. }\end{array}$ \\
\hline Functional Outcome & $\begin{array}{l}\text { Endpoint defined and a tangible means of assessment is } \\
\text { available to determine attainment. }\end{array}$ \\
\hline
\end{tabular}


Table 2. Analysis of 'outcomes' in Preparing for Practice by elements of style, ability to assess, and consideration of the learning environment

\begin{tabular}{|c|c|c|}
\hline Upon registration the GDC registrant will be able to:- & $\begin{array}{l}\text { Elements of } \\
\text { presentation style }\end{array}$ & $\begin{array}{c}\text { Narrative of the quality as an 'outcome', elements of educational style and impact of the } \\
\text { supervised learning environment }\end{array}$ \\
\hline 6.1 Put patients' interests first and act to protect them & $\begin{array}{l}\text { Standard / Outcome with } \\
\text { feasibility challenges }\end{array}$ & $\begin{array}{l}\text { The first part 'Put patients' interests first' is a standard. The second part is an outcome with the } \\
\text { action verb being 'Act', but how is this assessed? Within a supervised environment, the } \\
\text { supervising clinician is ultimately responsible for the patient and planning decisions, not the } \\
\text { student. The learner does not have the independence but can contribute to the process. }\end{array}$ \\
\hline 6.2 Be honest and act with integrity & $\begin{array}{l}\text { Standard / Outcome with } \\
\text { feasibility challenges }\end{array}$ & $\begin{array}{l}\text { Be honest' is a standard, 'act with integrity' is an outcome. No tangible outcome to assess. } \\
\text { Honesty and integrity would ideally be longitudinal qualities? Generally the concept is ok for the } \\
\text { learning environment. }\end{array}$ \\
\hline 6.3 Respect patients' dignity and choices & $\begin{array}{l}\text { Outcome with feasibility } \\
\text { challenges }\end{array}$ & $\begin{array}{l}\text { 'Respect' is technically an Outcome as it is in Bloom's taxonomy affective domain, but can you } \\
\text { assess an individual's value of something? Or really is it listen to and take account of? } \\
\text { Difficult to 'standardise' an assessment which will allow this to be demonstrated across a cohort. } \\
\text { Likely to demonstrate an occurrence, not longitudinal and multiple applications. }\end{array}$ \\
\hline 6.4 Maintain and protect patients' information & Functional Outcome & $\begin{array}{l}\text { Inference of IG compliance? A tangible outcome which can be assessed by current means. } \\
\text { Can be delivered by a learner in a supervised environment }\end{array}$ \\
\hline $\begin{array}{l}\text { 6.5 Recognise and respect the patient's perspective and } \\
\text { expectations of dental care and the role of the dental team taking } \\
\text { into account current equality and diversity legislation, noting that } \\
\text { this may differ in England, Scotland, Wales and Northern Ireland }\end{array}$ & $\begin{array}{l}\text { Outcome with feasibility } \\
\text { challenges }\end{array}$ & $\begin{array}{l}\text { Recognise' is not a good verb (although in Bloom's cognitive domain), how do you assess } \\
\text { someone's recognition? 'Respect' is an outcome, but how is this assessed? } \\
\text { Not clear as to the tangible outcome to be assessed. Many different elements included, it is } \\
\text { however possible to consider these elements in a learning / supervised environment. }\end{array}$ \\
\hline $\begin{array}{l}7.1 \text { Be familiar with and act within the GDC's standards and } \\
\text { within other professionally relevant laws, ethical guidance and } \\
\text { systems }\end{array}$ & $\begin{array}{l}\text { Objective / Outcome } \\
\text { with feasibility } \\
\text { challenges }\end{array}$ & $\begin{array}{l}\text { 'Be familiar with' is not an 'outcome', how do you measure 'familiarity'? Difficult to quantify as } \\
\text { encompasses a range of non-specified elements. Familiarity can be considered at a point in time, } \\
\text { but 'act within' implies a more longitudinal activity. Within a learning environment, challenges can } \\
\text { arise with the student's ability to display the full scope of activities indicated. }\end{array}$ \\
\hline $\begin{array}{l}\text { 7.2 Recognise and act upon the legal and ethical responsibilities } \\
\text { involved in protecting and promoting the health of individual } \\
\text { patients }\end{array}$ & $\begin{array}{l}\text { Objective / Outcome } \\
\text { with feasibility } \\
\text { challenges }\end{array}$ & $\begin{array}{l}\text { Very broad. Not obviously assessable as no specific tangible elements identified. } \\
\text { Challenging to consider in terms of equal opportunities to demonstrate for all students, within an } \\
\text { environment of supervision, a limited opportunities. }\end{array}$ \\
\hline $\begin{array}{l}7.3 \text { Act without discrimination and show respect for patients, } \\
\text { colleagues and peers and the general public }\end{array}$ & $\begin{array}{l}\text { Outcome with feasibility } \\
\text { challenges }\end{array}$ & $\begin{array}{l}\text { Difficult to quantify/assess. This is a longitudinal view and with disparate groups of people } \\
\text { mentioned this will happen at different times. Do ALL students actively have interactions with 'the } \\
\text { general public' which is distinct from 'patients' in a way that can be actively measured and } \\
\text { assessed? Requires assessment of a behaviour. }\end{array}$ \\
\hline $\begin{array}{l}\text { 7.4 Recognise the importance of candour and effective } \\
\text { communication with patients when things go wrong, knowing } \\
\text { how and where to report any patient safety issues which arise }\end{array}$ & Functional Outcome & $\begin{array}{l}\text { Recognise' is not a good verb, how do you assess someone's recognition? Describing the } \\
\text { importance of candour etc. and reporting of patient safety issues (i.e. protocols) can be assessed. } \\
\text { Clear articulation of a tangible outcome measure. Ok for a learner in a supervised environment. }\end{array}$ \\
\hline $\begin{array}{l}\text { 7.5 Take responsibility for and act to raise concerns about your } \\
\text { own or others' health, behaviour or professional performance as } \\
\text { described in Standards for the Dental Team, Principle } 8 \text { Raise } \\
\text { concerns if patients are at risk }\end{array}$ & $\begin{array}{l}\text { Outcome with feasibility } \\
\text { challenges }\end{array}$ & $\begin{array}{l}\text { In the context of a student environment / practice, are there recognisable opportunities for } \\
\text { demonstrating this available to all students? Knowledge about how, why and when to raise } \\
\text { concerns could be assessed, but the actual 'act' does not seem a universal and standardised } \\
\text { opportunity. }\end{array}$ \\
\hline $\begin{array}{l}8.1 \text { Describe and respect the roles of dental and other } \\
\text { healthcare professionals in the context of learning and working in } \\
\text { a dental and wider healthcare team }\end{array}$ & $\begin{array}{l}\text { Functional Outcome / } \\
\text { Outcome with feasibility } \\
\text { challenges }\end{array}$ & $\begin{array}{l}\text { The 'describe' element of the outcome can be assessed, but 'respect' although an outcome in } \\
\text { Bloom's affective domain is difficult to assess, the 'assessment' of 'failure to respect' is more } \\
\text { straightforward. Appropriate for a learner in a supervised environment. }\end{array}$ \\
\hline $\begin{array}{l}8.2 \text { Ensure that any team you are involved in works together to } \\
\text { provide appropriate dental care for patients }\end{array}$ & Objective & $\begin{array}{l}\text { Unsure how this could be assessed and whether it within the control of a student in the context that } \\
\text { they operate? Tangible outcome measures? }\end{array}$ \\
\hline
\end{tabular}




\begin{tabular}{|c|c|c|}
\hline Upon registration the GDC registrant will be able to:- & $\begin{array}{l}\text { Elements of } \\
\text { presentation style }\end{array}$ & $\begin{array}{c}\text { Narrative of the quality as an 'outcome', elements of educational style and impact of the } \\
\text { supervised learning environment }\end{array}$ \\
\hline $\begin{array}{l}8.3 \text { Explain the contribution that team members and effective } \\
\text { team working makes to the delivery of safe and effective high } \\
\text { quality care }\end{array}$ & Functional Outcome & $\begin{array}{l}\text { Explicit statement of what needs to be done to demonstrate attainment. Tangible, can be } \\
\text { assessed in a number of ways. Appropriate for a student in a learning environment. }\end{array}$ \\
\hline $\begin{array}{l}\text { 9.1 Recognise and demonstrate own professional responsibility } \\
\text { in the development of self and the rest of the team }\end{array}$ & $\begin{array}{l}\text { Outcome with feasibility } \\
\text { challenges }\end{array}$ & $\begin{array}{l}\text { How to assess someone's recognition of their own professional responsibility? What is an } \\
\text { appropriate 'level'? In the context of a student environment / practice, are there recognisable } \\
\text { opportunities for demonstrating development of 'the rest of the team'? Will a standardised } \\
\text { opportunity exist for all students? }\end{array}$ \\
\hline $\begin{array}{l}\text { 9.2 Utilise the provision and receipt of effective feedback in the } \\
\text { professional development of self and others }\end{array}$ & $\begin{array}{l}\text { Functional Outcome / } \\
\text { Outcome with feasibility } \\
\text { challenges }\end{array}$ & $\begin{array}{l}\text { Delivery of 'effective feedback' can be assessed. How someone uses feedback in their own } \\
\text { professional development is more difficult to tangibly determine/assess. A longitudinal, 'cause and } \\
\text { effect' action. Limited opportunity within a supervised learning environment in a finite programme. }\end{array}$ \\
\hline $\begin{array}{l}\text { 9.3 Explain the range of methods of learning and teaching } \\
\text { available and the importance of assessment, feedback, critical } \\
\text { reflection, identification of learning needs and appraisal in } \\
\text { personal development planning }\end{array}$ & Functional Outcome & $\begin{array}{l}\text { A fairly descriptive outcome which indicates what needs to be done to demonstrate attainment. } \\
\text { Ok for a learner in a supervised environment. }\end{array}$ \\
\hline $\begin{array}{l}\text { 9.4 Develop and maintain professional knowledge and } \\
\text { competence and demonstrate commitment to lifelong learning }\end{array}$ & $\begin{array}{l}\text { Outcome with feasibility } \\
\text { challenges }\end{array}$ & $\begin{array}{l}\text { No apparent tangible outcome, not time-bound. Maintaining professional knowledge is interesting } \\
\text { as the programme is a finite period. 'Demonstration of commitment to lifelong learning' could be } \\
\text { achieved, however for a student in a supervised learning programme, there is limited ownership. }\end{array}$ \\
\hline $\begin{array}{l}\text { 9.5 Recognise and evaluate the impact of new techniques and } \\
\text { technologies in clinical practice }\end{array}$ & $\begin{array}{l}\text { Outcome with feasibility } \\
\text { challenges / Functional } \\
\text { Outcome }\end{array}$ & $\begin{array}{l}\text { Again, 'recognise' is not a good verb - how do you assess recognition? 'Evaluate the impact' is } \\
\text { explicit. Appropriate for a student in a supervised environment. }\end{array}$ \\
\hline $\begin{array}{l}\text { 9.6 Accurately assess their own capabilities and limitations in the } \\
\text { interest of high quality patient care and seek advice from } \\
\text { supervisors or colleagues where appropriate }\end{array}$ & $\begin{array}{l}\text { Outcome with feasibility } \\
\text { challenges }\end{array}$ & $\begin{array}{l}\text { How do you assess the accuracy of someone's own assessment of their capabilities and } \\
\text { limitations? Difficult to standardise and monitor for each student, other than potentially a lack of } \\
\text { concerns raised. Longitudinal demonstration of insight. Appropriate for a learner in a supervised } \\
\text { environment. }\end{array}$ \\
\hline $\begin{array}{l}\text { 9.7 Explain and demonstrate the attributes of professional } \\
\text { attitudes and behaviour in all environments and media }\end{array}$ & $\begin{array}{l}\text { Functional outcome / } \\
\text { Outcome with feasibility } \\
\text { challenges }\end{array}$ & $\begin{array}{l}\text { 'Explain' can be assessed, however wide scope 'all environments and media'. 'Demonstrate' is } \\
\text { challenging as all students do not necessarily interact in all 'media', so challenging in terms of } \\
\text { equal opportunities. . Assessing an attitude is challenging, assessing the observable behaviours } \\
\text { may be more realistic. A longitudinal and multi-faceted remit, difficult to conclude attainment. }\end{array}$ \\
\hline
\end{tabular}


Figure 1. To show the process of document analysis of the Professionalism domain within the 'dentist' section of the Preparing for Practice ${ }^{1}$ document

\section{Data source overview}

- Overview of the GDC 'Preparing for Practice' document, its production, accessibility, applicability and format. Focus on the 'Professionalism' domain in the 'Dentists' section of the document.

Initial data analysis

- Establishing a database and sorting of data

-Identification of action verb within the LO and match to Bloom's taxonomy

\section{Production of summary documentation}

- Development of descriptors for statements in terms of their status as an educational goal (Table 1.)

Revision, final analysis of document and validation

-Assignment of learning 'status' following application of descriptors

- Identification of endpoint

- Ability to deliver in a supervised environment

- Review by members of research team 
Figure 2. Summary of challenges identified in both style of 'outcome' preparation and representativeness of professionalism

\section{Falling short of an outcome}

- No observable behaviour (lack of a tangible end-point) stated;

- Written in the style of standards and objectives as opposed to outcomes;

- Broad focus and multi-faceted elements, meaning assumptions by the researchers were needed in the analysis to judge achievement;

- Questionable achievability within a supervised environment and the confines of an undergraduate programme.

Why 'outcomes' present challenges in ensuring 'professionalism'

- Observable/assessable at moments in time yes, but will it be sustained behaviour?

- Can't assess it 


\section{References}

1. General Dental Council. Preparing for Practice: Dental team learning outcomes for registration (2015 revised edition). London: GDC, 2015 [Available from: https://www.gdcuk.org/professionals/education]

2. Harden RM, Crosby JR, Davis MH. AMEE Guide No. 14: Outcome-based education: Part 1-An introduction to outcome-based education. Med Teach. 1999;21(1):7-14.

3. Spady WG, Marshall KJ. Beyond traditional outcome-based education. Educational Leadership. 1991;49(2):67-72.

4. Bloom BS. Taxonomy of educational objectives, the classification of educational goals Handbook 1: cognitive domain. New York: McKay, 1956.

5. Krathwohl DR, Bloom BS, Masia BB. Taxonomy of Educational Objectives, the classification of educational goals- Handbook II: Affective Domain. New York: McKay, 1964.

6. Biggs JB, Collis KF. Evaluating the Quality of Learning: The SOLO Taxonomy. New York: Academic Press, 1982.

7. Fink LD. Creating significant learning experiences: An integrated approach to designing college courses. San Francisco: Jossey-Bass, 2003.

8. Oliver $\mathrm{R}$, Kersten $\mathrm{H}$, Vinkka-Puhakka $\mathrm{H}$, et al. Curriculum structure: principles and strategy. Eur J Dent Educ. 2008;12:74-84.

9. Bateman H, Ellis J, Stewart J, McCracken G. Using learning outcomes in dental education. $\mathrm{Br}$ Dent J. 2017;223:854-857.

10. Bateman HL, Ellis JS, Thomason JM. Virtual courses: enhancing a curriculum. Eur J Dent Educ. 2017;21:17-21.

11. Goldie J. Assessment of professionalism: a consolidation of current thinking. Med Teach. 2013;35(2).

12. O'Sullivan $\mathrm{H}$, van der Mook W, Fewtrell $\mathrm{R}$, Wass V. Integrating professionalism into the curriculum: AMEE Guide No. 61. Med Teach. 2012;34:e64-e77.

13. Manogue M, McLoughlin J, Christersson C, et al. Curriculum structure, content, learning and assessment in European undergraduate dental education - update 2010. Eur J Dent Educ. 2011;15:133-141.

14. General Medical Council. Outcomes for graduates (Tomorrow's Doctors). 2015 [Available from: http://www.gmc-uk.org/education/undergraduate/undergrad outcomes.asp]

15. Hodges BD, Ginsburg $S$, Cruess $R$, et al. Assessment of professionalism: Recommendations from the Ottawa 2010 Conference. Med Teach. 2011;33(5):354-363.

16. van Mook WN, van Luijk SJ, O'Sullivan $\mathrm{H}$, et al. The concepts of professionalism and professional behaviour: conflicts in both definition and learning outcomes. Eur J Intern Med. 2009;20(4).

17. Ginsburg S, Regehr G, Lingard L. Basing the Evaluation of Professionalism on Observable Behaviors: A Cautionary Tale. Acad Med. 2004;79(10):S1-S4.

18. Biesta G, Burbules, N. Pragmatism and educational research (Philosophy, theory, and educational research). Oxford: Rowman \& Littlefield, 2003.

19. Cornish F, Gillespie, A. A Pragmatist Approach to the Problem of Knowledge in Health Psychology. J Health Psychol. 2009;14(6):800-809.

20. Rapley T. Doing Conversation, Discourse and Document Analysis. 2nd ed. London: Sage, 2017.

21. Whittemore R, Chase SK, Mandle CL. Validity in Qualitative Research. Qual Health Res. 2001;11(4):522-537.

22. Jamieson S. Analyse qualitative data. Educ Prim Care. 2016;27(5):398-402.

23. Malterud K. Qualitative research: standards, challenges, and guidelines. The Lancet. 2001;358(9280):483-488. 
24. Varpio L, Ajjawi R, Monrouxe LV, O'Brien BC, Rees CE. Shedding the cobra effect: problematising thematic emergence, triangulation, saturation and member checking. Med Educ. 2017;51(1):40-50.

25. Richardson L, St Pierre EA. Writing: a method of inquiry. In: Denzizen N, Lincoln Y, editors. The Sage Handbook of Qualitative Research. 3rd ed. p. 959-978. Thousand Oaks, CA: Sage Publications; 2005.

26. Bateman HL, McCracken GI, Thomason JM, Ellis JS. Learning outcomes: Exploring implications of adopting a different level of detail. Eur J Dent Educ. 2018;22(2):86-91.

27. Rees CE, Knight LV. Viewpoint: The Trouble with Assessing Students' Professionalism: Theoretical Insights from Sociocognitive Psychology. Acad Med. 2007;82(1):46-50

10.1097/1001.ACM.0000249931.0000285609.0000249905. 